Technologies for Refueling Spacecraft On-Orbit

David J. Chato

Glenn Research Center, Cleveland, Ohio 
Since its founding, NASA has been dedicated to the advancement of aeronautics and space science. The NASA Scientific and Technical Information (STI) Program Office plays a key part in helping NASA maintain this important role.

The NASA STI Program Office is operated by Langley Research Center, the Lead Center for NASA's scientific and technical information. The NASA STI Program Office provides access to the NASA STI Database, the largest collection of aeronautical and space science STI in the world. The Program Office is also NASA's institutional mechanism for disseminating the results of its research and development activities. These results are published by NASA in the NASA STI Report Series, which includes the following report types:

- TECHNICAL PUBLICATION. Reports of completed research or a major significant phase of research that present the results of NASA programs and include extensive data or theoretical analysis. Includes compilations of significant scientific and technical data and information deemed to be of continuing reference value. NASA's counterpart of peerreviewed formal professional papers but has less stringent limitations on manuscript length and extent of graphic presentations.

- TECHNICAL MEMORANDUM. Scientific and technical findings that are preliminary or of specialized interest, e.g., quick release reports, working papers, and bibliographies that contain minimal annotation. Does not contain extensive analysis.

- CONTRACTOR REPORT. Scientific and technical findings by NASA-sponsored contractors and grantees.
- CONFERENCE PUBLICATION. Collected papers from scientific and technical conferences, symposia, seminars, or other meetings sponsored or cosponsored by NASA.

- SPECIAL PUBLICATION. Scientific, technical, or historical information from NASA programs, projects, and missions, often concerned with subjects having substantial public interest.

- TECHNICAL TRANSLATION. Englishlanguage translations of foreign scientific and technical material pertinent to NASA's mission.

Specialized services that complement the STI Program Office's diverse offerings include creating custom thesauri, building customized data bases, organizing and publishing research results ... even providing videos.

For more information about the NASA STI Program Office, see the following:

- Access the NASA STI Program Home Page at http://www.sti.nasa.gov

- E-mail your question via the Internet to help@sti.nasa.gov

- Fax your question to the NASA Access Help Desk at 301-621-0134

- Telephone the NASA Access Help Desk at 301-621-0390

- Write to: NASA Access Help Desk NASA Center for AeroSpace Information 7121 Standard Drive Hanover, MD 21076 


\section{Technologies for Refueling Spacecraft On-Orbit}

David J. Chato

Glenn Research Center, Cleveland, Ohio

Prepared for the Space 2000 Conference and Exposition sponsored by the American Institute of Aeronautics and Astronautics Long Beach, California, September 19-21, 2000

National Aeronautics and Space Administration

Glenn Research Center 
Trade names or manufacturers' names are used in this report for identification only. This usage does not constitute an official endorsement, either expressed or implied, by the National Aeronautics and Space Administration.

Available from

NASA Center for Aerospace Information

7121 Standard Drive

Hanover, MD 21076

Price Code: A03
National Technical Information Service 5285 Port Royal Road Springfield, VA 22100

Price Code: A03 


\title{
TECHNOLOGIES FOR REFUELING SPACECRAFT ON-ORBIT
}

\author{
David J. Chato \\ National Aeronautics and Space Administration \\ Glenn Research Center \\ Cleveland, Ohio 44135
}

\begin{abstract}
This paper discusses the current technologies for onorbit refueling of spacecraft. The findings of 55 references are reviewed and summarized. Highlights include: the Russian Progress system used by the International Space Station: a flight demonstration of superfluid helium transfer; and ground tests of large cryogenic systems. Key technologies discussed include vapor free liquid outflow, control of liquid inflow to prevent liquid venting, and quick disconnects for onorbit mating of transfer lines.
\end{abstract}

\section{INTRODUCTION}

On-orbit refueling is a subject of great interest to many spacefarers. Future missions such as human exploration of the solar system and space based laser missile defense systems require filling in low gravity with large quantities of cryogenic propellants. A recent Air force paper ${ }^{1}$ has shown substantial benefits to even more mundane missions such as a follow-on global positioning satellite (GPS) constellation. Every space station since Salyut-6 is refueled routinely with storable propellant. The new International Space Station is no exception. However the recent cancellation of plans to resupply the U.S. Propulsion Module indicate the level of risk and uncertainty inherent in this operation. This paper attempts to make plain what is known about refueling in an effort to assist the community in understanding and mitigating the risk of these operations. The author will focus on fluid management since this is his area of expertise. He will touch on the important subjects of rendezvous, docking, extravehicular activity, and spacecraft parts accessibility only as they relate to fluid systems. One final note: refueling systems must be planned and designed into spacecraft prior to launch, retrofitting systems on-orbit is well nigh impossible for reasons which will be come apparent as the technical discussion progresses.

Fluid systems for resupply can be subdivided into three components, the supply tank, the transfer line, and the receiver tank. The supply tank must be emptied of liquid without ingesting vapor and maintain a level of pressure sufficient to accomplish the transfer quickly. The transfer line must connect the two tanks with a minimum of fluid loss, be conditioned to the required operating parameters, and maintain a low pressure drop. Hardware challenges include reliable docking mechanisms; transfer line disconnects capable of sealing against the vacuum of space and low heat leak transfer systems. The filling of receiver tanks in low gravity poses the most technical challenges. Fluid management challenges include the uncertainty of liquid and vapor distributions in a tank in low gravity, the need to keep maximum tank pressure low to reduce tank mass, and for cryogenic liquids the large rate of generation of vapor from the residual energy stored in tank walls. During a normal gravity fill, a top vent is kept open to vent the vapor generated during the fill process, thereby maintaining a low tank pressure. If the same approach is used in low gravity, the ullage gas may never vent. Instead of venting vapor, large amounts of liquid may be dumped overboard. If liquid is vented from one side of a non-propulsive vent and vapor from the other side, the spacecraft may tumble out of control. The spacecraft can be placed in an 
artificial gravity field by continuous thruster firing to position the ullage at a vent opening, but this may require dedicated thrusters and additional propellant. For the fill operation, maintaining control between the tanker spacecraft and the spacecraft being refueled while thrusting may be difficult due to potentially large shifts in the center of gravity. In places, such as a depot based at a space station, thrusting may be impractical due to large system size.

This paper will discuss the current state-of-the-art for refueling on-orbit. Topics to be addressed include the history of refueling, recent advances, and opportunities for further investigation. Finally future planned and potential activities to advance the state-of-the-art will be presented. As will be seen as the discussion proceeds what is the ideal solution for one propellant may not even be implementable in another. To facilitate the understanding of what is unique and what is common the discussion of transfer systems is broken down in to three parts. The first part is simulant testing and modeling, which is applicable to all systems. The second part is storable systems. Finally, the third part is cryogenic systems.

\section{DISCUSSION}

\section{SIMULANT TEST AND MODEI.ING}

Liquid outflow has been investigated extensively in the drop tower. Bernyi and Abdalla ${ }^{2}$ showed that zero-g outflow without baffling results in a high level of interface distortion. This distortion results in vapor ingestion at very high fill levels (as much as $34 \%$ full). As a result most modern spacecraft rely on Propellant Management Devices (PMD) to outflow liquid. Two main types of PMD have emerged, the screen channel and the vane device. The screen channel relies on the surface tension forces of the liquid in a fine pore size screen to form a barrier to vapor. Vapor cannot enter the wetted screen until it overcomes the pressure force created by surface tension. Typically a screen is used as one side of a hollow channel. Multiple channels are arranged throughout the tank to maximize contact with the bulk liquid. Individual channels can be tested by laying them horizontal in normal gravity (usually screens are capable of withstanding no more than a few inches of pressure head). The Shuttle reaction control system (RCS) ${ }^{3}$ shows a typical design. Vanes use thin pieces of rigid material to form a shape that is preferentially wet with liquid in zero-g. The classic example of this design is that of the Viking Orbiter. ${ }^{4}$ The vane technique has the advantage that bubbles in the retained liquid do not destroy its performance. It is also frequently lighter and lower cost. It has the disadvantage that it cannot not be tested in normal gravity. These two techniques can be combined using vanes to retain liquid over the outlet and screen as a final barrier to vapor ingestion. The PMD in reference 5 is an example of this.

Symons ${ }^{6-8}$ along with Symons and Staskus ${ }^{9}$ studied the stability of liquid inflow in zero-g by conducting a series of drop tower tests. The tests used various room temperature liquids and clear tanks to observe the behavior of liquid flowing into a tank. In most tests the momentum of the incoming flow formed a columnar geyser of liquid. The crucial question for stability was whether the geyser continued to grow in height during the fill or if the surface tension forces were sufficient to cause the geyser to subside into the accumulating liquid. This phenomenon is important because a growing geyser will splash the vent, dumping liquid overboard before the tank is full. A bounding Weber number (ratio of momentum to surface tension forces) of 1.5 (using the radius of the jet at the free surface as the characteristic dimension) was found to be the limit at which the geyser would not continue to grow. For most fluids, this Weber number corresponds to a rather low flow rate, so, Staskus ${ }^{10}$ undertook to determine if stability could be improved by baffling. The results indicated that for the best baffling studied (a series of stacked washers capped with a disk over the inlet and a ring baffle on the tank wall) the stable Weber number was 12 times greater than for the unbaffled case. Finally, Spuckler ${ }^{11}$ looked at the effect of accelerations from 0.003 to 0.015 times the force of earth normal gravity $(\mathrm{g})$ on the inflow process and was able to correlate geyser height as a function of Weber and Bond Numbers (the Bond number is the ratio of momentum to accelerational forces). Aydelott ${ }^{12}$ address the problem of tank mixing with a liquid jet rather than inflow, but his correlations for geyser height as a function of flow rate and gravity level are important to transfer as well. Dominick and Tegart ${ }^{13}$ were able devise a system that used a vane PMD as the inflow baffle, combining inflow and outflow devices. This was demonstrated on a small scale in drop tower tests.

Recent Shuttle fluid management flight experiments have improved our understanding of fluid management in low gravity. Notable experiments include: Storable Fluid Management Device (SFMD)/ Fluid Acquisition 
and Resupply Experiment (FARE) which used a common set of hardware to explore several different transfer schemes, ${ }^{14-17}$ Tank Pressure Control Experiment (TPCE) ${ }^{18-22}$ that examined pressure control and tank mixing; and Vented Tank Resupply Experiment (VTRE) ${ }^{23}$ that looked at a vane device to separate gas and liquid.

SFMD/FARE hardware flew in the shuttle middeck. It consists of two plastic spheres about 12.5" in diameter filled with air and water. One of the tanks had an elastomeric membrane that ensured positive expulsion. The second tank was filled with different test articles dependant on the flight. Details of the hardware can be found in Kirkland and Tegart. ${ }^{14}$ SFMD flew on STS $51 \mathrm{G}$ in January of 1985 . The bottom of its second tank was filled with a four channel screened liquid acquisition device. The top half contained a series of baffle plates (four horizontal and six radial perforated plates). A maximum fill of about $85 \%$ was achieved at a maximum flow rate of $1 \mathrm{gpm}$. The baffles were not as successful as expected in preventing liquid from entering the vent line. They are also a large intrusive structure, which is undesirable. FARE I replaced the half tank screen channel with a full tank one and added a inlet with a small baffle plate over it similar to Staksus. FARE I demonstrated fill up to the $70 \%$ level without liquid venting and a stable inlet Weber number of 2.3. FARE II replaced both of these devices with a vane fluid management that served both as a liquid acquisition device and an inlet baffle. FARE II demonstrated fill up to $95 \%$ without liquid venting at a maximum flow rate of $0.35 \mathrm{gpm}$. The low vapor pressure of water at room temperature meant that none of these has to face the issues of boiling and pressurant evolution found in many propellants, The use of a surfactant to lower the contact angle of water and wet the walls resulted in problems with foaming that are also unrepresentative of propellants.

TPCE has flown three times. The first flight focused on the mixing studies of Aydelott. ${ }^{13}$ Improvements included actual heat transfer data by using a condensing fluid (refrigerant 113) and longer duration low gravity. Bentz ${ }^{18-20}$ was able to confirm the geysering and circulating regimes of Aydelott, but encountered an asymmetric regime between the two that was even more catastrophic to heat transfer than aft collection. The second flight of TPCE focused mostly on rapid boiling phenomena, but contains some further tests on mixing. Hasan ${ }^{21}$ confirms the findings of Bentz. The third flight ${ }^{22}$ was done at a lower fill level but confirms the results of the other flights.

VTRE used two clear 0.8 cubic foot tanks, one spherical and one with a short barrel section, and transferred refrigerant 113 between them as well as venting it to space. Tests included retention of liquid during transfer, liquid free venting, and recovery of liquid into the PMD after thruster firing. Liquid was retained successfully at the highest flow rate tested $(2.73 \mathrm{gpm})$. Liquid free vents were achieved for both tanks, although at a higher flow rate $(0.1591 \mathrm{cfm})$ for the spherical tank than the other $(0.0400 \mathrm{cfm})$. Recovery from a thruster firing that moved the liquid to the opposite end of the tank from the PMD was achieved in 30 seconds.

CFD modeling of the refueling problem has advanced the understanding of the processes involved. It has been used to study mixing, slosh, and reorientation, as well as predict the forces caused by the liquid on the rest of the spacecraft. Until recently low gravity data has not been available to validate CFD results. Analytical work is listed in references 24-32. Concus ${ }^{24-25}$ provides differential equations of the free surface problem, but analyzes only static cases. Hochstein ${ }^{26-27}$ analyzes the microgravity mixing with a volume of fluid approach, but uses only a limited approximation to model the surface tension. Aydelott ${ }^{28}$ and Der $^{29}$ both analyze the motion of a bubble in the oxygen tank during separation of a Centaur stage with VOF models; noteworthy in these is again the appearance of a geyser. Tegart ${ }^{30}$ shows the application of the Surface Evolver code of Brakke ${ }^{31}$ to actual tank shapes. Tegart also uses this model to examine the results of FARE II. ${ }^{17}$ Brackbill ${ }^{32}$ develops an improved surface tension model for VOF codes, but only shows one example of its use for axial jets.

\section{STORABLESYSTEMS}

Resupply of storable propellant has been routinely conducted by the Progress module on Russian space stations since 1978. The Russian system is not well documented in the western literature. The most commonly sited source is Feoktistov, ${ }^{33}$ but an English translation is not publicly available. Janes ${ }^{34}$ contains a brief but thorough explanation. Another account can be found in Clark. ${ }^{35}$ To avoid the problems of phase separation a flexible membrane separates the liquid 
from the pressurant gas. Then the liquid can be transferred by pressurizing the tank without worrying about ingesting vapor. Drawbacks of this system include life of the membrane, weight and an inability to deal with vapor evolved from the bulk liquid. Nevertheless the Progress module includes resupply tanks holding about $870 \mathrm{~kg}$ of propellant (two tanks of nitrogen tetroxide and two of UDMH hydrazine). High-pressure nitrogen is used as the pressurant. A compressor is used to lower pressure in the receiver tank by transferring nitrogen back into high-pressure storage bottles. After the lines have been leak checked the fuel then oxidizer are transferred one at a time to the station. Separate transfer for each reduces the hazard in case of a leak. The process can be controlled either by a ground station or the space station crew. This module and system where first used on Saylut 6 on Jan 20, 1978 and have been used on every space station since including Mir, and ISS. ISS had its first refueling August 2000.

The Orbital Refueling System (ORS) Flight Demonstration was a low cost system to demonstrate propellant transfer. Built by the NASA Johnson Space Center (JSC) and also using bladders and hydrazine this system flew on STS-41G launched October 5, 1984. Six transfer tests moved a maximum of $142 \mathrm{~kg}$ back and forth. Astronauts also conducted EVA to mate a simulated transfer line to a connector similar to that used on Landsat for ground fueling. Details where never fully published but a summary of results and photo of the EVA tools is found in Griffin. ${ }^{36}$ One of the important findings of ORS was the heating of pressurant gas behind the bladder. It turned out the transfer rate was limited by a desire to keep temperatures from reaching the decomposition temperature of hydrazine $(200 \mathrm{~F})$. The transfer process was controlled to limit ullage gas temperatures to $150 \mathrm{~F}$. Kauffam ${ }^{37}$ gives a detailed analysis and post flight reconciliation to the test data. Unfortunately the ORS instrumentation was limited to one temperature sensor for each tank mounted on the sidewall external to the tank so actual ullage gas temperatures are unknown.

NASA has funded several efforts to develop a reliable coupling for on-orbit servicing. Cardin ${ }^{38}$ details the development of the universal refueling interface system (URIS) a unique coupling in that it contains the docking mechanism, fluid transfer coupling, and electrical connectors. This coupling was initially developed with Moog, Inc. internal research funds but later supported by both JSC and NASA Marshall Space
Flight Center(MSFC). JSC demonstrated servicing with mock-up couplers in the Manipulator Development Facility. A complete rendezvous and docking was planned for the MSFC Flat Floor Facility, but test results are unpublished. $\mathrm{Moog}^{39}$ developed and tested a fully operational quick disconnect from these concepts to support the stringent leakage and sealing requirements of the space station ammonia cooling loop. Although space station redesign eliminated the cooling loop system the connector was pressure checked to the burst pressure of $1465 \mathrm{psi}$, vibrated to levels of $13.1 \mathrm{Gs}$ and mated and demated over 350 times. Gorin ${ }^{40}$ discusses a fluid servicing system designed by Fairchild that was also tested in the JSC facility.

\section{CRYOGENIC SYSTEMS}

SUPERFLUID HELIUM The Super Fluid On-Orbit Transfer (SHOOT) flight demonstration, ${ }^{41}$ build by the NASA Goddard Space Flight Center, was launched June 21, 1993 on STS-57. It consisted of two liquid helium vacuum insulated tanks (dewars) plumbed together. It contained a screen channel device in one tank and a vane device in the other tank. Transfers where conducted with the use of a thermal mechanical (TM) pump, which uses the unique property of superfluid helium to move in the direction of warmest temperature to move the fluid back and forth. The helium was launched as normal boiling point fluid and converted to superfluid helium by venting down through a porous plug. After the conversion was complete 152 liters of fluid were available for test. This liquid was expended in the course of six transfers back and forth. Because the TM adds heat to the system some helium is lost in each transfer. Transfer from the vane side was tested to a maximum of 720 liters/hour. Transfer from the screen channel side was limited to a maximum of 385 liters/hour by cavitation in the TM. Although the SHOOT experiment was very successful its reliance on the unique properties of superfluid helium make application of its results to other fluids difficult. A superfluid helium coupling was developed by $\mathrm{Moog}^{42}$ under contract from NASA be used on SHOOT. It used the same basic design as the Moog quick disconnects described previously. To meet the stringent requirements of liquid helium vacuum jacketed insulation was added to the coupler and some support structures redesigned to minimize conduction heat loads. Unfortunately cost constraints prevented this coupling from being flown on SHOOT. 
CRYOGENIC PROPELLANT SYSTEMS Systems for cryogen propellants such as liquid hydrogen and liquid oxygen have unique challenges. The large scale of the systems for which these propellants are attractive makes any in-tank structure large and complex. No membrane material that can be used at cryogenic temperatures has been found. Elastomeric membranes have poor cycle life in liquid oxygen and hydrogen diffuses through at an unacceptable rate..$^{43}$ At these low temperatures metal membranes suffer from poor flexibility and limited life due to cracking.

For small tanks the two-phase problem can be avoided by raising the pressure above the point where there is a sharp transition between liquid and gas (also known as the critical pressure). For hydrogen this is an easily obtainable $188 \mathrm{psia}$; for oxygen it is a more problematical $731 \mathrm{psia}$. This system is used for storage and supply of hydrogen and oxygen for the shuttle Power Reactant Supply and Distribution system. ${ }^{44}$ Unfortunately Arif ${ }^{45}$ demonstrated that a propulsion stage designed to these pressures would be incapable of moving itself from low earth orbit to geosynchronous orbit let alone with any payload.

One promising concept for propellants that can be pressurized with its own vapor (such as oxygen and hydrogen) is a procedure known as no-vent fill. This procedure uses liquid subcooling to recondense vapor back into the incoming liquid. For tanks, which are warm and dry, a chilldown procedure is used to remove wall energy and a sacrificial quantity of cryogen is vented overboard as vapor prior to the start of the fill. Space venting can also be used to remove noncondensable pressurant such as helium from tanks which are burned to depletion, prior to the start of the fill process.

One of the earliest detailed designs of an orbital fluid transfer system is found in Morgan, et al.$^{46}$ This study was in support of post-Apollo, manned, interplanetary missions and evaluated six tanker concepts. The smallest tankers were designed for launch on a Saturn $V$ rocket; the largest tankers were for a post-Saturn rocket 70 feet in diameter. All tankers were selfpropelled using one or two RL10 engines. The Morgan designs for LO2 and LH2 tankers were based on analysis of the thermodynamics of the fill process. The baseline transfer system used a 6 -inch transfer line with a 30-minute transfer time. This required a $117-1 \mathrm{~b} / \mathrm{sec}$ flow of LO2 and $31.6 \mathrm{lb} / \mathrm{sec}$ flow of LH2. An analysis of the receiver tank (in this case a Saturn IIB stage) was conducted for both venting and nonvented transfer from a starting temperature of $400 \mathrm{R}$. Venting losses for the tank were $13,400 \mathrm{lbs}$ of $\mathrm{LH} 2$ and $5,620 \mathrm{lbs}$ of LO2. The no-vent fill analysis indicated that a $90 \%$ fill could be obtained with a final tank pressure of 25 psia for LO2 and 53 psia for LH2. One of the recommendations of this report was to conduct a smallscale orbital cryogenic propellant transfer experiment. A compilation of many more system concepts can be found in Chato. ${ }^{47}$

Recent large-scale cryogenic ground testing programs have demonstrated liquid hydrogen no-vent fill capability with near-flightweight hardware. Analytical modeling techniques verified by these tests showed that the process can be implemented over a broad range of tank sizes, and modeled to show the effect of size on the process. Research at NASA Glenn has focused on both the development of analytical models for simulating the process in conceptual designs and the practical demonstration of the method in an extensive ground test program. References 48 and 49 documented tests with a large $\left(175 \mathrm{ft}^{3}\right)$ tank at NASA/GRC's K-Site facility. These tests demonstrated the impact of varying critical input parameters, such as the liquid inlet mass flow rate and the initial tank wall temperature, on the no-vent fill process. Although due to the nature of the test setup liquid inlet temperature could not be parametrically investigated, run-to-run variations in inlet temperature seemed to have significant effects on the final fill pressure. Reference 50 reports the results of a test series for filling a $71-\mathrm{ft} 3$ tank with liquid hydrogen without venting. 22 tests were conducted, 10 with a bottom orifice as the inlet and 12 with a spray bar. Parameters investigated included inlet saturation pressures of approximately 5,15 , and 25 psia, transfer pressures of 20,30 , and 45 psia, and various starting wall temperatures. Of the tests, only the one run at the highest wall temperature (238 R) failed to fill the tank. Test results are compared to a thermodynamic equilibrium model. Overall model-data agreement was good except for the tendency of the model to overshoot during the initial wall cooldown of the higher starting wall temperature fills. This suggests that a small-scale test is adequate to provide information on the effects of low gravity on the process.

Small-scale flight test concepts are also found in Chato. ${ }^{47}$ Some of the more well known are CFMF ${ }^{51}$ a shuttle payload bay experiment similar to SHOOT, and 
COLD-SAT ${ }^{52-54}$ a large free flying satellite experiment in support of the SEI initiative. The author's concepts for a small sounding rocket experiment of more limited scope are found in reference 55 . Unfortunately none of the concepts have progressed beyond the critical system design and no flight hardware has been fabricated.

\section{CONCLUDING REMARKS}

The era of on-orbit refueling is at hand. Currently the only operational system is the Russian progress module, but many more systems are close at hand. A concept for Superfluid Helium has been flight demonstrated. Cryogenic propellant systems are ready for a flight demonstration. What is required now is funding to move these concepts from the laboratory benchtop to proven reliable systems for spacecraft. A good deal can be accomplished with modest funds for small-scale demonstrations, but testing in the relevant environment will require launch into space.

\section{REFERENCES}

1. Leisman, G. A. and Wallen, A. D., "Design and Analysis of On-Orbit Servicing Architectures for the Global Positioning System Constellation." Masters Thesis, Air Force Institute of Technology, March 1999.

2. Berenyi, S. G. and Abdalla, K. L., "Vapor Ingestion Phenomenon in Hemispherically Bottomed Tanks in Normal Gravity and in Weightlessness," NASA TN D-5704, April 1970.

3. Fester, D. A. Eberhardt, R. N. and Tegart, J. R., "Space Shuttle Reaction Control Subsystem Propellant Acquisition," AIAA 74-1106, October 1974.

4. "Viking Orbiter 1975 System Support, Final Report, Part 2, Propulsion Hardware," SE-00947-01, JPL Contract 953261, Martin Marietta Corporation, Feb 1974.

5. Purohit, G. P., Smolko, J. W., and Ellison, J. R., "Propellant Management Device Performance During an Off-Nominal Transfer Orbit Mission," AIAA 98-4033, July 1998.

6. Symons, E.P.; Nussle, R.C. and Abdalla, K.L., "Liquid Inflow to Initially Empty, Hemispherical Ended Cylinders During Weightlessness," NASA TN D 4628, June 1968.

7. Symons, Eugene P., Nussle, Ralph C., "Observations of Interface Behavior During
Inflow to an Elliptical Ended Cylinder in Weightlessness," NASA TM X-1719, January 1969.

8. Symons, Eugene P., "Interface Stability During Liquid Inflow to Initially Empty Hemispherical Ended Cylinders in Weightlessness," NASA TM X-2003, April 1970.

9. Symons, Eugene P., Staskus, John V., "Interface Stability During Liquid Inflow to Partially Full, Hemispherical Ended Cylinders in Weightlessness," NASA TM X-2348, August 1971.

10. Staskus, John V, "Liquid Inflow into a Baffled Cylindrical Tank During Weightlessness," NASA TM X-2598, August 1972.

11. Spuckler, Charles M. "Liquid Inflow to Initially Empty Cylindrical Tanks in Low Gravity," NASA TMX-2613, August 1972.

12. Aydelott, J.C., "Modeling of Space Vehicle Propellant Mixing," NASA TP-2107, January 1983.

13. Dominick, S. M. and Tegart, J. R., "Low-G Propellant Transfer Using Capillary Devices," AIAA Paper 81-1507; 1981

14. Kirkland, Z. and Tegart, J., "On-Orbit Propellant Resupply Demonstration," AIAA 84-1342, June 1984.

15. Tegart, J. and Kirkland, Z., "On-Orbit Propellant Resupply Demonstration -Flight Test Results," AIAA 85-1233, July 1985.

16. Dominick, S. and Driscoll, S., "Fluid Acquisition and Resupply Experiment (FARE I) Flight Results," AIAA 93-2424, June 1993.

17. Dominick, S. and Tegart, J., "Orbital Test Results of a Vaned Liquid Acquisition Device," AIAA 94-3027, June 1994.

18. Bentz, M.D., et al. "Tank Pressure Control Experiment - A Low-g Mixing Investigation," AIAA 90-2376.

19. Bentz, Michael D., "Tank pressure control in low gravity by jet mixing," NASA-CR-191012, March 1993.

20. Bentz, M. D, Knoll, R. H, Hasan, M. M, Lin, C. S., "Low-g fluid mixing - Further results from the Tank Pressure Control Experiment," AIAA PAPER 93-2423, Jun. 1993.

21. Hasan, Mohammad M., Lin, Chin S., Knoll, Richard H., and Bentz, Michael D., "Tank Pressure Control Experiment: Thermal Phenomena," NASA TP 3564, March 1996. 
22. Bentz, Michael D, et. al., "Tank Pressure Control Experiment - Results of three space flights," AIAA Paper 97-2816, July 1997.

23. Chato, D. J; and Martin, T. A., "Vented Tank Resupply Experiment - Flight Test Results," AIAA 97-2815, July 1997.

24. Concus, P., "Capillary Stability in an Inverted Rectangular Tank," Adv, Astro. Sc. Vol 14., pp. 21-37, 1963.

25. Concus, P., "Static Menisci in a Vertical Right Circular Cylinder," J. Fluid Mech. Vol 34, part 3 pp. 481-495, 1968.

26. Hochstein, J.I., Gerhart, P.M., Aydelott, J.C., "Computational Modeling of Jet Induced Mixing of Cryogenic Propellants in Low-G," AIAA 841344.

27. Hochstein, J. I., "Computational Modeling of Jet Induced Mixing in Cryogenic Propellant Tanks in Low-G," Ph.D. Thesis, The University of Akron, 1984.

28. Aydelott, J.C., et al., "Numerical Modeling of On-Orbit Propellant Motion Resulting from an Impulsive Acceleration," NASA TM-89873, 1987.

29. Der, J.J., Stevens, C.L., "Low-Gravity Bubble Reorientation in Liquid Propellant Tanks", AIAA 87-0622, January 1987.

30. Tegart, James, "Three-Dimensional Fluid Interfaces in Cylindrical Containers" AIAA 912174, June 1991.

31. Brakke, K. A. "Surface Evolver Manual" Minimal Surface Team of the Geometry Supercomputer, Available via $\mathrm{ftp}$ at geom.umn.edu

32. Brackbill, J.U., Kothe, D.B., Zemach, C., "A Continuum Method for Modeling Surface Tension," Journal of Computational Physics $v 100$ n2, June 1992.

33. Feoktistov K. P. "Nauchnyy Orbital'nyy Kompleks," (Novoye v zhizni, nauke tekhnike. Seriya Komsmavtika, Astronomiya No 3, 1980), "Znaniye" Press 1980 pp. 1-64.

34. Wilson, A. Ed, Jane's Space Directory Twelfth ed. 1996-1997, Article on Progress pp 23-24, 1996.

35. Clark, P., The Soviet Manned Space Program, Orion Press pp. 94-96.

36. Griffin, J. W., "Background and Programmatic Approach for the Development of Orbital Fluid Resupply Tankers, AIAA 86-1601, June 1986.
37. Kauffman, D., "An Analysis of Ullage Heat Transfer in the Orbital Refueling System", JSC20912.

38. Cardin. J., "A Standardized Spacecraft Resupply Interface," AIAA 91-1841, June 1991.

39. Farrell, W. F. Jr., "Fluid Quick Disconnect Coupling for International Space Station Alpha," AIAA 95-2353, July 1995.

40. Gorin, B. F., Gonzalez, A. E., “A Berthing, Fluid and Electrical Interface Mechanism and Fluid Couplings for Spacecraft Servicing On-Orbit." Johns Hopkins Univ., The 1989 JANNAF Propulsion Meeting Vol. 1, May 1989.

41. DiPirro, M., Shirron, P. and Tuttle, J.,"On-Orbit Superfluid Transfer: Preliminary Results from the SHOOT Flight Demonstration." Cryogenics v.34 n.5, 1994.

42. Ryder, M. O., Morash, D. H., and Schoenburg, R. J., "Superfluid Helium Resupply Coupling," Johns Hopkins Univ., The 1989 JANNAF Propulsion Meeting Vol. 1, May 1989.

43. Lark, R. F. "Cryogenic Positive Expulsion Bladders," NASA TM X-1555, April 1968.

44. Wagner, H. A., Space Shuttle Orbiter Power Reactant Storage and Distribution Subsystem Handbook Fourth Edition, JSC 26269, July 1993.

45. Arif, H., Aydelott, J. C., and Chato, D. J., "Evaluation of Supercritical Transfer Systems for Future NASA Missions," Journal of Propulsion and Power v8 n2, March 1992 pp 332-338.

46. Morgan, L. L. et al, "Orbital Tanker Design Data Study" Volume II, Lockheed Missiles and Space Co. LMSC-A748410, May 1965.

47. Chato, D. J., "Cryogenic Transfer Options For Exploration Missions," AIAA 91-354, September 1991.

48. Chato, D.J., "Ground Testing on the Nonvented Fill Method of Orbital Propellant Transfer: Results of Initial Test Series," AIAA 91-2326, June 1991.

49. Taylor, W. J. and Chato, D. J., "Comparing the Results of an Analytical Model of the No-Vent Fill Process with No-Vent Fill Test Results for a $4.96 \mathrm{~m}^{3}\left(175 \mathrm{ft}^{3}\right)$ Tank," AIAA-92-3078, July 1992.

50. Chato, D. J., "Ground Testing for the No-Vent Fill of Cryogenic Tanks: Results of Tests for a 71 Cubic foot Tank," AIAA 93-1967, June 1993.

51. Eberhart, R. N., et al, "Cryogenic Fluid Management Facility Concept Definition Study (CFMF)," Martin Marietta Denver Aerospace, NASA CR 174630, December 1983. 
52. Bailey, W. J. et al, "Cryogenic On-Orbit Liquid Depot Storage, Acquisition and Transfer Satellite (COLD-SAT) Feasibility Studies," Martin Marietta Space Systems Co., NASA CR 185247, June 1990.

53. Schuster, J. R., Russ, E. J. and Wachter, J. P., "Cryogenic On-Orbit Liquid Depot Storage, and Transfer Satellite (COLD-SAT)" General Dynamics Space systems Division and Ford Aerospace Space Systems Division, NASA CR185249, July 1990.

54. Rybak, S. C. et al, "Feasibility Study for a Cryogenic On-Orbit Liquid Depot-Storage, Acquisition and Transfer (COLD-SAT) Satellite," Ball Aerospace Systems Group, NASA CR-185248, August 1990.

55. Chato, D.J., and Taylor W. J., "Small Experiments for the Maturation of Orbital Cryogenic Transfer Technologies," NASA Technical Memorandum 1055849, August 1992. 

Public reporting burden for this collection of information is estimated to average 1 hour per response, including the time for reviewing instructions, searching existing data sources, gathering and maintaining the data needed, and completing and reviewing the collection of intormation. Send comments regarding this burden estimate or any other aspect of this Davis Mighway, Suite 1204, Arlington, VA 22202-4302, and to the Office of Management and Budget, Paperwork Reduction Project (0704-0188), Washington, DC 20503.
\begin{tabular}{|l|l|l} 
1. AGENCY USE ONLY (Leave blank) & $\begin{array}{c}\text { 2. REPORT DATE } \\
\text { November } 2000\end{array}$ & $\begin{array}{r}\text { 3. REPORT TYPE AND DATES COVERED } \\
\text { Technical Memorandum }\end{array}$
\end{tabular}
\begin{tabular}{|l|l|l} 
1. AGENCY USE ONLY (Leave blank) & $\begin{array}{c}\text { 2. REPORT DATE } \\
\text { November } 2000\end{array}$ & $\begin{array}{r}\text { 3. REPORT TYPE AND DATES COVERED } \\
\text { Technical Memorandum }\end{array}$
\end{tabular}
3. REPORT TYPE AND DATES COVERED

4. TITLE AND SUBTITLE 5. FUNDING NUMBERS

Technologies for Refueling Spacecraft On-Orbit 6. AUTHOR(S)

David J. Chato

7. PERFORMING ORGANIZATION NAME(S) AND ADDRESS(ES)

National Aeronautics and Space Administration

John H. Glenn Research Center at Lewis Field

Cleveland, Ohio 44135-3191

WU-242-33-0A-00

9. SPONSORING/MONITORING AGENCY NAME(S) AND ADDRESS(ES)

National Aeronautics and Space Administration

Washington, DC 20546-0001

8. Performing organization

REPORT NUMBER

E-12472

10. SPONSORINGMONITORING AGENCY REPORT NUMBER

NASA TM-2000-210476

AIAA-2000-5107

11. SUPPLEMENTARY NOTES

Prepared for the Space 2000 Conference and Exposition sponsored by the American Institute of Aeronautics and Astronautics, Long Beach, California, September 19-21, 2000. Responsible person, David J. Chato, organization code 5870, 216-977-7488.

12a. DISTAIBUTIONAAVAILABILITY STATEMENT

12b. DISTAIBUTION CODE

Unclassified - Unlimited

Subject Category: 34

Distribution: Nonstandard

Available electronically at http://gltrs.grc,nasa.gov/GLTRS

This publication is available from the NASA Center for AeroSpace Information. 301-621-0390.

13. ABSTRACT (Max/mum 200 words)

This paper discusses the current technologies for on-orbit refueling of spacecraft. The findings of 55 references are reviewed and summarized. Highlights include: the Russian Progress system used by the International Space Station: a flight demonstration of superfluid helium transfer; and ground tests of large cryogenic systems. Key technologies discussed include vapor free liquid outflow, control of liquid inflow to prevent liquid venting, and quick disconnects for onorbit mating of transfer lines.

\section{SUBJECT TEAMS}

Fluid management; Orbit transfer vehicles; Cryogenics; Storable propellants

15. NUMBER OF PAGES

17. SECURITY CLASSIFICATION
OF REPORT
Unclassified

18. SECURITY CLASSIFICATION OF THIS PAGE

Unclassified
19. SECURITY CLASSIFICATION OF ABSTRACT Unclassified 
= 